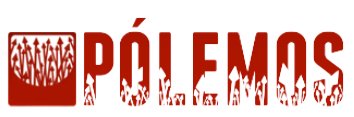

\section{Acerca do Tratado sobre o não-ser de Górgias}

Gabrielle Cavalcante Brígido

Mestranda- UnB

\begin{abstract}
Resumo: Pretende-se aqui uma breve interpretação do Tratado sobre o não-ser, de Górgias, tentando expor qual a posição do autor a respeito da relação que existiria entre realidade/verdade, pensamento e discurso. Vemos nesse tratado uma forte crítica da identidade entre ser, pensar e dizer que é operada pela ontologia de Parmênides. Crítica essa elaborada a partir das consequências mais extremas do próprio Poema do eleata. Pensamos, portanto, que é a partir dos enunciados do texto parmenidiano que Górgias pode efetuar a separação entre ser, pensar e dizer, não havendo para o sofista qualquer relação de continuidade entre os três. Dessa forma, o discurso perde a sua tradicional função de transmissor de conhecimento/pensamento de um indivíduo a outro, de comunicador da verdade, pois não haveria uma "verdade primeira" que pudesse nos ser revelada através do discurso. Sendo assim, Górgias remete-nos à autonomia do discurso, o que nos possibilita espaço para pensarmos qual função poderia ele então exercer. Pode-se então atribuir aos discursos o papel de estabelecedores da realidade.
\end{abstract}

Palavras-chave: Górgias; Sofística; Ontologia; Discurso; Filosofia Clássica.

Abstract: This work intends to make an brief interpretation of On Non-Existence by Gorgias. The text tries to show this author's point of view about the relation between reality/truth, thinking and speech. In Gorgias' work we can see a strong criticize to Parmenidean ontology, which takes being, thinking and speaking as equal. This criticism is made from the extreme consequences of Parmenides' Poem. Therefore, we believe Gorgias would make his distinction between being, thinking and speaking from the Parmenidean text's propositions. There is not any equating between these three concepts to the sophist. Thus, speech loses its usual role as vehicle of knowledge/ thinking from a person to another, or carrier of the truth, because there is no "first truth" that could be uncovered by the speech. Under these circumstances, Gorgias approximates his thinking to the notion of speech's autonomy. This becomes possible the questioning of which role can the speech plays. Then, we can put the speech in the role of establisher of reality.

Keywords: Gorgias; Sophistic; Ontology; Speech; Classical Philosophy. 


\section{Introdução}

Devemos dizer de saída que o trabalho aqui proposto não pretende trazer uma resposta definitiva às questões levantadas, antes, é um exercício de interpretação que encontra-se ainda - e, talvez, enquanto dure - em aberto. Sabemos que comumente Górgias e os demais "sofistas" são interpretados a partir da caracterização presente nos diálogos de Platão e que ainda quando essas interpretações partem diretamente de seus textos - esta mesma caracterização é responsável, em parte, por uma variedade de classificações que frequentemente prejudicam a tentativa de compreensão de seu pensamento. Assim, na lista de conceitos associados a Górgias podemos encontrar "sofista", "retórico", "relativista", “cético", "fenomenólogo", "niilista". Nosso ponto de partida, então, tenta não se assentar em tais visões exteriores ao texto de Górgias em questão, mas antes, tenta, na medida do possível, combatê-las com as questões oferecidas pela argumentação no texto do próprio Górgias. Combatê-las não para lhe atribuir um novo conceito na sua já extensa lista, mas porque cremos que conceituá-lo, identificá-lo, "capturá-lo" - como queria Platão - é, antes de mais nada, incoerente com os pontos de vista que o próprio Górgias combate em sua perspectiva.

O texto "original" do seu Tratado intitulado Sobre o não-ser ou sobre a natureza ${ }^{l}$

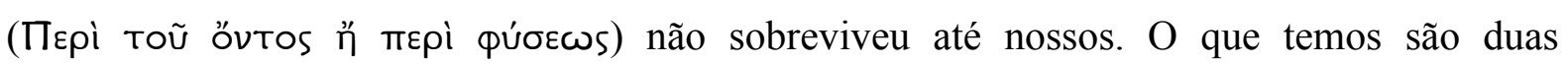
paráfrases: uma atribuída a Sexto Empírico (Adversus Mathematicos, VII, 65-87) e outra a um autor anônimo, na terceira parte de um opúsculo pseudo-aristotélico, De Melisso, Xenófanes e Górgias, designado pela sigla $D e M^{2}$ (979 a 12-980 b22) onde são estabelecidas logo de saída suas três famosas teses: 1) Nada é (Oưk Eĩvaí [...] oưóve, $M X G$,

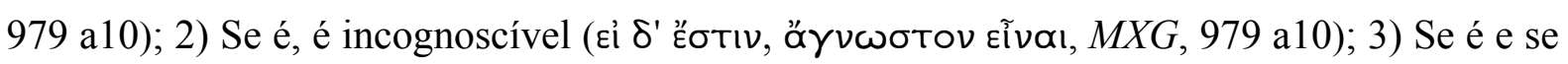

\footnotetext{
${ }^{1}$ Doravante o chamaremos de Tratado.

${ }^{2}$ Essa obra apresenta alguns problemas, tanto em relação à sua autoria e seu objeto quanto pelo seu precário estado de preservação, algumas passagens estão bastante danificadas. Muitas e divergentes são as conjecturas sobre a autoria e a datação: pertenceria a Aristóteles, a Teofrasto, a um peripatético do III século antes de Cristo, a um eclético do primeiro século de nossa era, a um cético ou a um megárico. À parte isso, ainda hesitou-se sobre a identidade dos dois filósofos tratados nas duas primeiras seções, mas jamais sobre a de Górgias devido à concordância com a versão de Sexto Empírico. A nós não interessa aqui defender uma posição sobre o assunto, nem alongarmos a discussão, apenas nos serviremos da obra - e de suas traduções ao português - para nossos propósitos.
} 


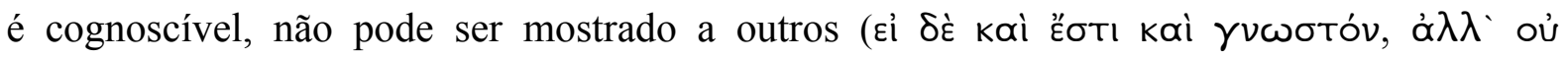
$\delta \eta \lambda \omega$ Tòv à $\lambda \lambda$ oıs, $M X G, 979$ a10).

Controversas têm sido as interpretações acerca desse Tratado e do pensamento de Górgias. Em linhas muito gerais podemos dizer que de um lado estão os que colocam o Tratado como simples exercício retórico, desqualificado como um "jogo", feito com o intuito apenas de deslumbrar e persuadir a audiência - o que o destituiria de uma importância filosófica -, e de outro, os que veem no Tratado uma crítica ao pensamento de Parmênides ou ao eleatismo e uma expressão do niilismo, ceticismo ou relativismo de Górgias.

Diferente, e no nosso ponto de vista mais interessante, é a análise feita por Bárbara $\operatorname{Cassin}^{3}$ que interpreta o Tratado como um discurso segundo, crítico de um primeiro discurso, o Poema ${ }^{4}$ de Parmênides, de onde provém boa parte da ontologia platônico-aristotélica. Como dito no parágrafo anterior, a interpretação do Tratado como crítica à ontologia de Parmênides e ao eleatismo não é novidade, mas Cassin a faz com uma abordagem diferente, vendo nessa crítica um caráter lógico-discursivo e não empirista ou fenomenológico como era comumente visto pelos estudiosos. Propõe que o discurso de Górgias não refuta o Poema por conta de uma preocupação com o mundo sensível, com uma adequação às coisas, mas sim por uma maior atenção ao próprio discurso, começando pelo de Parmênides.

Górgias, não seria então um niilista, relativista, ou cético, não é que ele afirme dogmaticamente que não exista verdade, ou que ela é relativa a cada um, ou ainda que não exista um critério para se alcançá-la. Ele constataria, nesse Tratado, que o próprio enunciado de identidade da ontologia de Parmênides - o Ser é Ser - não se sustenta, e mais ainda, se desmente a si mesmo. Assim sendo, não há nada que justifique, além do discurso, que o Ser é a verdade e o não-ser não o é. O poema ontológico seria então uma simples "obra" do discurso, uma possibilidade que se autolegitima como tantas outras.

Parece-nos então que - deixando claro que sempre a partir de certa leitura desse Tratado e dos outros textos remanescentes de Górgias ${ }^{5}$-, apesar de não encontrarmos uma "teoria" bem formada acerca do conhecimento e da linguagem nos fragmentos de Górgias, é

\footnotetext{
${ }^{3}$ CASSIN, Barbara. "A ontologia como obra-prima sofística", in O efeito sofistico. Trad. bras. Ana Lúcia de Oliveira e Maria Cristina Franco Ferraz. Rio de Janeiro, Editora 34, 2005. pp. 16 e 17. O presente trabalho baseia-se essencialmente nesse artigo e na interpretação feita por Cassin. De agora em diante em todos os momentos que a autora for citada nos referiremos a esse texto, quando não a devida referência será feita.

${ }^{4}$ DK 28 B 1-9. Onde são estabelecidas três teses: a) que existe o Ser e somente ele é, enquanto o não-ser não é; b) que, por essência, esse Ser é cognoscível, dado que Ser e pensar são o mesmo; c) e que, a partir disso, era possível transmitir esse conhecimento do Ser através da fala.

${ }_{5}^{5}$ Elogio de Helena (DK 82 B 11) e a Defesa de Palamedes (DK 82 B 11a).
} 
possível encontrar alguns elementos que nos fazem deduzir uma nova forma de pensar a linguagem e o discurso e sua relação com o conhecimento, a saber, a língua não poderia representar a realidade concreta ou a verdade e também perderia sua função de transmissora de conhecimento de um indivíduo ao outro. Entretanto, nem por isso a realidade é negada ou relativizada por Górgias, nem a palavra seria "inutilizada" por essa limitação, pelo contrário, essa limitação tornaria a palavra mais "poderosa" ainda, pois ela seria "algo" autônomo capaz de "fabricar" o mundo, fazer com que ele advenha, em outras palavras, a palavra seria responsável justamente por plasmar a realidade.

\section{Do que não é}

Comecemos por evocar as palavras da deusa no fragmento II do Poema de Parmênides. Só existiriam dois únicos caminhos de busca em que se pode pensar: de um lado o que é e que não é possível não ser, a verdade, mas também - não podemos deixar de lembrar - "caminho de persuasão" e do outro o que não é e que é necessário não-ser e isso é tudo, não se pode conhecer ou dizer a identidade do "não é", portanto, a deusa ordenava que se evitasse o segundo caminho. Primeira tese de Górgias: "nada é”.

Para a primeira tese "nada é", segundo o doxógrafo anônimo, Górgias faz uso de duas demonstrações: uma, diz ele, bem própria ao estilo de Górgias e outra que combina as teses contraditórias de outros eleatas (no texto vemos citados apenas Zenão e Melisso). Sexto usa no seu texto quase todo o mesmo material para sua argumentação, entretanto, utiliza-se deles, explicitamente, para outros propósitos, com uma finalidade cética: abolir o critério de

verdade. É assim que sua demonstração baseia-se unicamente no sujeito. Não é possível encontrar um sujeito que convenha ao caminho do "é”, e assim ele deduz que nada é, mas simplesmente porque não há coisa alguma para ser, pois nenhum dos sujeitos possíveis resiste, nem o não-ser, nem o ser, nem separadamente, nem juntos.

Já no texto do anônimo, como dissemos há pouco, duas são as demonstrações e em dois níveis distintos. Uma se baseia no sujeito - a que combina as teses dos outros eleatas -, e prova que nada é porque se nenhum predicado convém ao sujeito é sinal de que não existe mesmo algo para ser. A outra se baseia no verbo - a que é considerada própria de Górgias -, 
e prova que nada é porque nem "ser" nem “não-ser" sustentam-se em posição de verbo, pois não existe um verbo para ser. Portanto, é duplamente necessário concluir que "nada é".

Primeira demonstração ${ }^{6}$ :

se no entanto o não-ser é, o ser, diz ele, seu oposto, não é. Com efeito, se o não ser é, é conveniente que o ser não seja. De modo que, nesse caso, diz ele, nada seria, desde que não seja a mesma coisa ser e não ser. Mas se é a mesma coisa, nesse caso também nada seria: com efeito, o não-ente não é, tal como o ente, se pelo menos ele é a mesma coisa que o não-ente ${ }^{7}$

Górgias justifica sua tese na segunda demonstração fazendo uma crítica às noções de gerado e não-gerado, uno e múltiplo, utilizando-se de Zenão e Melisso, contrapondo-os para mostrar que nenhum desses predicados podem ser atribuídos ao ente. Uma vez que se algo "é" ou é gerado ou eterno, ou uno ou múltiplo e todas essas hipóteses foram refutadas uma a uma por ele, "nada existe".

Agora voltemos nosso olhar à análise de Cassin daquela que é considerada a demonstração própria de Górgias (que no anônimo é anunciada em segundo lugar), examinando - primeiramente - com cuidado a frase que a anuncia: "Não é [possível] nem ser

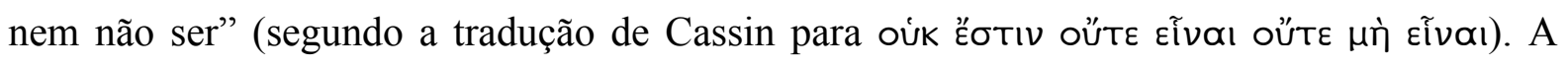
autora nos expõe que essa frase imita e completa o final do verso 3 do fragmento II do

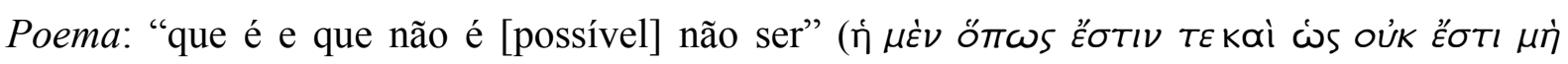
Eĩvaı). A fórmula de Górgias seria então homonímica e anfibólica. Homonímica porque ela joga com todos os sentidos do verbo ser (E๐TIV) que pode tanto ser verbo de existência, como cópula, como um impessoal marcando a possibilidade. Anfibólica porque, dependendo do sentido de EoTıv três construções são possíveis:

se se trata do verbo de existência, então os dois infinitivos têm função de sujeito: "nem o ser nem o não ser existem"; em se tratando da cópula, eles são os predicados de um sujeito que, normalmente, pode estar em elipse: "não é

\footnotetext{
${ }^{6}$ É importante atentar ao fato de que o doxógrafo anônimo critica essa conclusão de Górgias, pois a partir do mesmo argumento de que o ente e o não-ente são o mesmo, podemos concluir seu oposto, ou seja, que ambos existem e assim "tudo seria" e não necessariamente nada.

${ }^{7}$ Os trechos de Górgias que forem citados de agora em diante foram todos retirados da tradução de Cassin que se encontra ao final da versão brasileira do Efeito Sofístico, quando não as devidas referências serão feitas. Apesar de ser uma tradução da tradução, comparamos ao grego e julgamos ser a que mais se aproxima da nossa leitura.
} 
nem ser nem não ser"; com a modalidade enfim, os infinitivos se tornam completivos: "não é possível nem ser nem não ser" (p. 21).

Não devemos então excluir qualquer um dos três sentidos para a frase, pois eles se complementam nem tampouco ver como "simples brincadeira" ou defeito a homonímia e ambiguidade da argumentação, pois é, antes, o uso bem determinado de um recurso da língua grega, recurso esse já explorado por Parmênides no seu Poema, e o que está em jogo é justamente tornar evidente a exploração desse recurso na nascente ontologia.

Após anunciar sua tese, ele tenta demonstrá-la da seguinte forma: "pois se o não ser $e ́$ não ser, o não-ente seria não menos que o ente: com efeito, o não-ente é não-ente assim como o ente, ente, de modo que são, bem como não são, as coisas efetivas".

Para tentar entende-la voltemos mais uma vez ao Poema. A deusa ordena - como já foi dito - que se evite a segunda via, ou seja, o "caminho" do não-ser. Górgias se contenta em seguir essa ordem e também não se engaja no caminho do não-ser - pois se fizesse isso estaria cometendo uma violência totalmente externa ao Poema, enquanto o que ele quer é mostrar a falha no enunciado de identidade de Parmênides -, mas, para que se possa evitar o caminho proibido é preciso antes identificá-lo como tal. Dessa forma, nos diz Cassin ${ }^{8}$ :

O ponto de partida mínimo do reengajamento filosófico é então uma proposição do tipo não é não é ou o não ser é não ser. Mas essa simples proposição, de uma exigência mínima, já é catastrófica. Pois, desde que é engatada, nada pode deter o processo de identidade, ele se desenrola conforme à descrição que dele fornece Parmênides para o é - ou antes conforme aquilo que se efetua no e pelo Poema - de tal forma que o verbo, por essa aplicação predicativa de si a si mesmo, advém efetivamente como sujeito. O não ser é não ser, assim como o ser é ser [...]

Portanto, quando enunciamos apenas o verbo "é”, é impossível saber se o sujeito com o qual lidamos - seja nas frases ou no mundo - é como o não-ente ou como o ente. Assim sendo, é impossível então saber se estamos seguindo de fato o caminho do "é" ou apenas o do "não-é”, pois o próprio ato de diferenciar, demarcar claramente qual via deve ser seguida ou não, produz a indistinção dos dois.

Pois bem, ao tentar então aplicar a mesma proposição de identidade ao "não-é", Górgias acaba "descobrindo" a falha dessa proposição, porém ele não se aproveita dessa

\footnotetext{
${ }^{8}$ CASSIN, Barbara. Identidade e catástrofe ou como o cisne se torna elefante. In: Ensaios sofísticos. Trad. bras. Ana Lúcia de Oliveira e Lúcia Cláudia Leão. São Paulo, Siciliano, 1990, pp. 25 e 26.
} 
falha para se "refugiar" no não-ser, mas antes, torna manifesto que Parmênides é quem se aproveita do equívoco entre cópula e existência que o seu enunciado de identidade produz. É a ontologia nascente que cria um jogo de palavras, utilizando-se desse equívoco, para erigir o "Ser" como regra.

No caso da identidade do Ser - "o ser é ser" - a diferença entre sujeito e predicado torna-se imperceptível, já que tanto "o ser é" quanto "o ser é ser" se confirmam e se confundem, assim como os sentidos de existência e cópula do "é". Dessa forma é que Parmênides pode explorar esse equívoco do "é" para instituir o "ser" como regra. Mas, ao aplicar o mesmo processo ao "não-é", Górgias nos expõe claramente a falha, pois como a identificação do sujeito necessita da sua repetição como predicado e a afirmação da identidade entre os dois, no caso do "não-é" o resultado que se chega é o enunciado de sua diferença. Porque com o "não-ser é não-ser" os dois termos tornam-se distintos. Ele ao mesmo tempo existe e não existe. ${ }^{9}$

Dessa forma, Górgias mostra que o ser da ontologia não é nada além de um efeito da língua, ou seja, o "ser" é produzido pela linguagem e toda identificação dele se apoia no equívoco entre existência e cópula - aquele mesmo equívoco que tanto acusam os sofistas de explorarem - e assim podemos perceber também que o discurso dele não deseja simplesmente colocar "o mundo da doxa no trono da aletheia" (p. 15) e não refuta o Poema por uma preocupação com a adequação ao "mundo sensível”, mas sim por uma maior atenção ao próprio discurso.

\section{Se existe, é incognoscível}

\footnotetext{
9 Algo que Platão também percebe, posteriormente, e tenta solucionar no seu diálogo Sofista, propondo através do Estrangeiro de Eleia o gênero do Outro como aquilo que é responsável por fazer a conexão entre as diversas formas inteligíveis. Dando certa existência, então, ao não-ser e cometendo, dessa forma, o que ele próprio chama de parricídio. Notemos, contudo, que o suposto parricídio é feito tendo em vista apenas "salvar" a existência do Ser já estabelecida pelo pai assassinado, não sendo, portanto, de fato um "assassinato" do pensamento de Parmênides como aquele que lemos no Tratado. A alteridade exposta por Platão no Sofista existe apenas como fundamento para a existência das Formas e desse Ser. Platão percebe que o Ser só pode existir (e, talvez, ser comunicado) na medida em que existam coisas diferentes dele, ou seja, na medida em que exista o não-ser. O que Górgias faz é radicalizar ao extremo o pensamento de Parmênides para de fato "matá-lo" e demonstrar que tanto o Ser quanto o não-ser não existem. Em outras palavras, essa noção de Ser enquanto fundamento da realidade não pode demonstrar qualquer característica das coisas e qualquer discurso que tente falar do real nessa esfera da abstração está fadado à incoerência.
} 
Então, admitamos agora que exista esse Ser e que devemos de fato nos afastar do "não-ser", mas para isso seria preciso fazer exatamente o que fez Górgias na tese anterior: dizer o "não é" para poder identificar o "é”, porém a própria deusa nos diz no Poema que não é possível sequer dizermos ou pensarmos o "não ser". Como então poderíamos conhecer esse Ser sem sequer poder identificá-lo? Sem poder diferenciá-lo do que não é? Mais ainda, se o "não é" não pode sequer ser dito, porque a deusa o evoca?

Górgias, segundo o texto do anônimo, passa à demonstração da segunda tese do Tratado com a seguinte afirmação: "Se então nada é, as demonstrações dizem tudo sem exceção". E podemos dizer que não é por acaso, pois, uma vez que se descobriu que o "ser" é uma "invenção" do discurso não haveria outra verdade senão a que é argumentada. Assim, a crítica à ontologia retorna como tese discursiva: "o ser parmenideano é apenas um efeito de dizer, mas isso porque não há outro ser senão o que é produzido pelo dizer” (p. 49). Mas vejamos como isso se dá a partir do Poema de Parmênides.

Vemos repetidamente no interior do Poema a relação que existe entre ser e dizer: é dito que o ser se diz e que o não-ser não deve e sequer pode ser dito, para o não-ser resta uma não linguagem, "sons". Mais ainda, como nos diz o célebre fragmento III: "é a mesma coisa ser e pensar”. Portanto, ser, pensar e dizer estão intrinsecamente associados e não poderíamos sequer pensar - muito menos dizer - o que não existe.

Tendo então o Poema como premissa, ele nos diz ao iniciar sua demonstração no texto do anônimo: "É preciso que aquilo que é pensado seja, e que o não-ente, se ele realmente não é, tampouco seja pensado". Mas, ressalva Górgias, "se assim é, ninguém diz que algo falso não seria nada, mesmo se dissesse que carroças lutam em pleno mar, pois todas essas coisas seriam." Ou seja, partindo das premissas de Parmênides, o falso, a mentira, o erro, a ficção existiriam tanto quanto o verdadeiro logo que fossem pensados e falados. E é por isso também que as coisas vistas ou ouvidas existem, porque são igualmente pensadas. Portanto, se algo existe ou não, não pode ser conhecido por nós.

Como percebe Cassin, Górgias nos expõe a impossibilidade do pseûdos, no sentido de que não é possível discerni-lo da verdade. Não é que não exista o pseûdos, ele existe tanto quanto qualquer coisa - inclusive o Ser de Parmênides - no momento mesmo em que é concebido ou falado. Górgias não nega, então, que os pensamentos possam ser verdadeiros ou falsos, mas tão somente que é impossível diferenciá-los “objetivamente”, não há um 
critério "seguro" para isso, pois é impossível termos uma representação "adequada" coisas.

Portanto, vemos mais uma vez Górgias tentar desmontar a ontologia de Parmênides a partir de um desenvolvimento "extremo" das suas próprias premissas, pois as afirmações de que "o ser é" e "o não-ser não é" bem como a relação que existe entre ser, pensar e dizer é que produzem a indistinção do verdadeiro e do falso. E, mais uma vez, o ser é um efeito do dizer, mas dessa vez, de acordo com Cassin, é feita uma reivindicação da logologia ${ }^{11}$, por isso Górgias inicia nos dizendo que "as demonstrações dizem tudo sem exceção", pois, dado que nada é da maneira que a ontologia nos fez crer, não existe outra possibilidade de alcançarmos a verdade, a realidade - melhor dizendo, "construirmos" a realidade - senão persuadindo. A priori - pedindo licença quanto ao anacronismo do termo - não há nada que possamos conhecer ou revelar a outrem através do discurso.

Mas vejamos agora também - de uma forma bem mais breve - o que traz a argumentação de Sexto, apenas para evidenciarmos a diferença entre ambos os textos. Ela é um pouco mais extensa que a do anônimo, mas a dedução que ela produz não depende das teses de Parmênides, ao contrário, ela as nega. Ela conclui que o ente é incognoscível não porque basta ser pensado para ser, mas porque afirma que o ente não é pensado. De início é

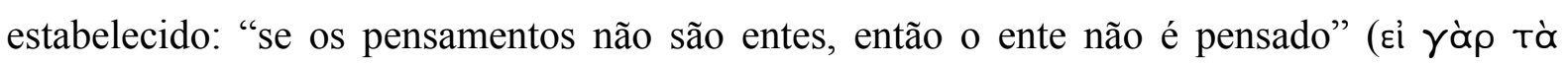

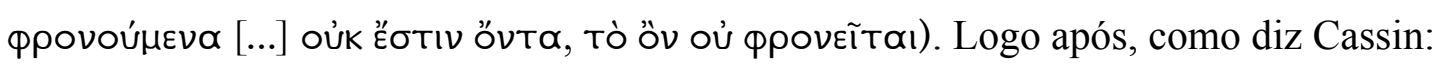

[...] demonstra duas vezes a premissa pelo absurdo: de início, se os pensamentos fossem entes, então bastaria ser pensado para ser, e carroças correriam sobre o mar - não haveria pseudos; em seguida, se os pensamentos fossem entes os não-entes não seriam pensados; ora, não param de sê-los, como testemunham Sila ou Quimera - mais uma vez, não haveria pseudos. (p. 38)

As duas argumentações tem intenções inversas, no De $M X G$ tomam-se as premissas do Poema ao pé da letra para tirar suas consequências mais extremas, enquanto no texto transmitido por Sexto recusam-se as premissas opondo-lhes a força igual, o que parece ser tão

\footnotetext{
${ }^{10}$ Entendamos adequada no sentido de corresponder a uma suposta realidade "primeira", ou seja, a um suposto Ser das origens.

${ }^{11}$ Um termo que ela toma emprestado de Novalis para descrever essa percepção da ontologia como discurso; essa autonomia do discurso que "fabrica" o mundo. Portanto, nessa segunda tese, Górgias não só percebe que o ser é um efeito do dizer, como parece querer tornar evidente que a única forma de se ter a verdade é construindo-a através de discursos.
} 
evidente quanto as premissas de Parmênides. Por isso, mais uma vez, seguimos o texto do anônimo para concluir nossa leitura: é apenas a partir da ontologia de Parmênides tomada ao pé da letra e levada até seu extremo que Górgias expõe o ser como um efeito do dizer e reivindica a realidade como sendo "fabricada" pelo discurso.

\section{Se existe e se pode ser conhecido, é incomunicável}

Finalmente chegamos à terceira e última tese de Górgias, aqui se segue a mesma estrutura de recuo das teses anteriores. Suponhamos agora que exista algo e que nos é possível conhecê-lo. Será possível também transmitir esse conhecimento a outrem? Górgias responde negativamente a essa pergunta partindo, primeiramente, da seguinte argumentação ${ }^{12}$ : que "coisas" não são palavras e não podem ser convertidas em palavras, pois seus domínios não são o mesmos.

Diz ele que pela visão não nos podem ser transmitidas as coisas audíveis, pois somente o que é visível pode ser percebido pela visão, nem as coisas visíveis podem ser transmitidas pela audição, pois somente o que é audível pode ser percebido pela audição; de modo que também pela palavra não nos pode ser transmitido outra coisa senão palavra; ora, as "coisas", os "seres" - como preferimos chamar - não são palavras, portanto, não podem ser transmitidos por elas.

Fica então evidente que os diversos domínios sensoriais não são homogêneos, e a cada um cabe "perceber" coisas específicas e sendo assim não há qualquer possibilidade de se transitar entre um e outro: nem o olho vê um som, nem o ouvido ouve uma cor. Da mesma forma, sendo a palavra diferente das coisas, dos sons, das cores, ela não permitirá que o falante transmita a outrem aquilo que viu ou ouviu, pois ela não diz nem uma cor, nem um som, mas um dizer. Há, portanto, um fosso intransponível entre os objetos "exteriores", a percepção que temos deles e as palavras, não há forma de conciliação.

No texto do anônimo, Górgias segue com uma argumentação que não tem equivalente em Sexto, diz ele que mesmo que fosse possível a alguém conhecer algo e dizer esse algo que conhece não haveriam garantias de que o ouvinte tivesse na ideia a mesma coisa que alguém

\footnotetext{
12 Novamente nos deparamos com argumentos distintos nas duas versões, entretanto, em ambas Górgias inicia utilizando-se desse argumento que separa os órgãos e os campos sensoriais. Na versão de Sexto, porém, ela é melhor desenvolvida.
} 
tem quando enuncia o discurso e apresenta três motivos para isso: primeiro, a mesma coisa não poderia estar em vários lugares separados, se assim fosse dois seriam então um; segundo, além disso, mesmo que uma coisa pudesse estar em vários lugares permanecendo a mesma, por conta dos indivíduos não serem semelhantes as coisas seriam percebidas de formas distintas e nada garantiria que um ouvinte tenha percebido uma coisa exatamente como outro percebeu; por último, nem em um único indivíduo as percepções são sempre semelhantes, elas variam de acordo com o tempo, o que alguém percebe hoje de dada coisa não é necessariamente a mesma coisa que percebia em um tempo passado e, muito provavelmente, não será a mesma também em um tempo futuro. E conclui dizendo: “Assim, se há algo cognoscível, ninguém poderia mostrá-lo a outrem, porque as coisas não são dizeres, e

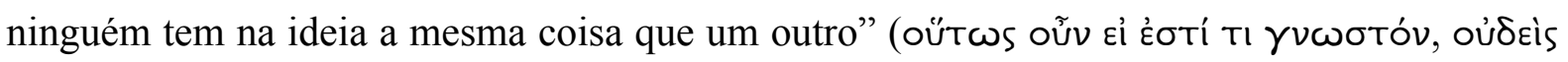

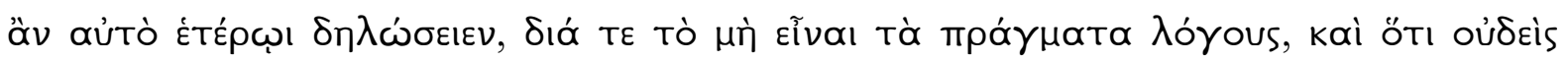

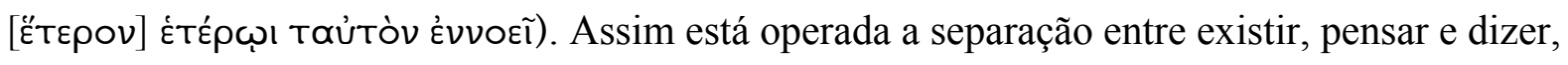
mas essa separação - ou inversão de Parmênides - implica exatamente em que? O que podemos estabelecer a partir do discurso de Górgias e dessa autonomia do lógos? Sendo então autônoma e incapaz de expressar a "realidade", a linguagem, ou melhor, a palavra serve exatamente para que?

Antes de concluirmos e tentarmos responder estas questões, voltemos nossa atenção mais uma vez ao texto de Sexto, lá encontramos uma passagem que não tem equivalente na versão do anônimo e é considerada como difícil por muitos comentadores, mas que pode também - dependendo do sentido que se atribua aos termos em grego - ser muito explicativa dessas questões que foram colocadas.

Eis então o argumento: o discurso se constitui a partir das coisas que nos vêm de fora, ou seja, das coisas sensíveis, pois é do encontro com o sabor que formamos um discurso sobre o sabor e igualmente com todas as coisas que percebemos. Sendo assim, diz, "o discurso não é comemorativo do de fora, é o de fora que se torna revelador do discurso" (Eỉ

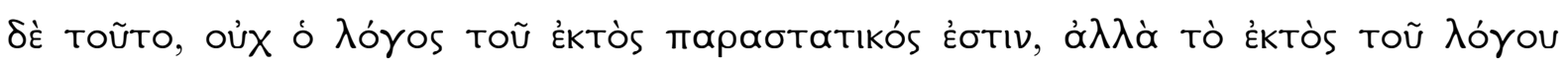

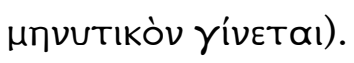

De acordo com Cassin, aqui tudo depende da tradução que dermos aos dois adjetivos

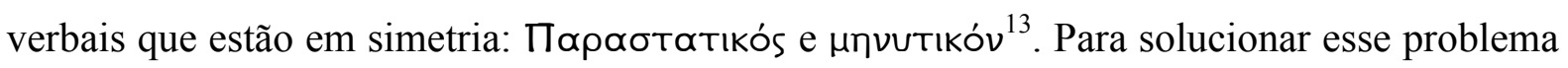

13 O primeiro termo é normalmente entendido como "o que explica", "o que faz compreender", "o que expõe".
A dificuldade maior reside no segundo termo, segundo a autora nunca se conseguiu conservar o mesmo 
a autora procede a um exame do uso que Sexto faz do termo em todas as ocorrências. E é no capítulo 3 do livro VII de Adversus Mathematicos que o termo mais aparece, onde Sexto faz uma crítica cética da semiologia dogmático-estóica. São distinguidos dois tipos de signos: o "comemorativo" e o "indicativo". O primeiro é signo das coisas que são ocasionalmente nãoevidentes (por exemplo, Atenas quando estou em outro lugar). Esse signo é chamado de comemorativo, pois apenas junta duas percepções em que frequentemente observamos conexão. Uma dessas percepções está ausente, mas é então rememorada e em qualquer modalidade de tempo, passado, presente ou futuro, por exemplo, uma cicatriz que lembra uma antiga ferida; a fumaça que indica fogo; o ataque cardíaco que pode anunciar a morte.

Já o indicativo é signo das coisas não-evidentes, coisas que por natureza não são observáveis em si e por isso ele contém em si "toda a mostração". Aqui temos como exemplo os movimentos do corpo que "indicam" a existência da alma (coisa que naturalmente escapa aos nossos sentidos).

Cassin se pergunta então qual o significado desses adjetivos tendo esse contexto em vista e afirma que o termo é usado para os dois tipos de signos indiferentemente. Mais ainda, na única frase em que os dois termos foram usados conjuntamente (VIII, 202) - e isso, segundo a helenista é aceito por todos os intérpretes que ela tem notícia - é Пđapaotatıós

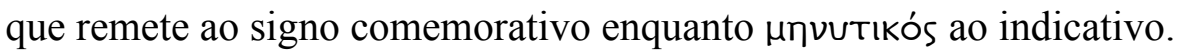

Assim sendo, a autora propõe uma tradução da frase ao "idioma de Sexto" que seria: "o discurso não é comemorativo do de fora é o de fora que se torna o signo indicativo do discurso", ou seja, o discurso não serve nem para lembrar nem para guardar na memória uma afecção exterior, mas o de fora funciona como "esses signos recusados por Sexto, e que servem para os dogmáticos deduzirem aquilo que, por natureza, escapa à nossa apreensão" (p. 62).

Por isso, o termo que melhor se encaixaria na intenção de Górgias, segundo a autora, seria "revelar" e a frase ficaria melhor construída nos seguintes termos: "Não é o discurso que comemora o de fora, é o de fora que se torna revelador do discurso", ou seja, o discurso não tem que representar o real, pois ele nem mesmo pode fazer isso, ele nem faz referência a nada exterior a ele, seja isso uma coisa ou uma ideia, nem ocupa o lugar de qualquer coisa.

sentido para todas as ocorrências do termo no texto de Górgias. MnvúEıv significa "revelar", "fazer conhecer", "indicar", "comunicar". E é esse último sentido que privilegiam em geral, mas, com ele, a frase acaba por não dizer mais nada. 
Ao contrário, levando em conta tudo o que foi exposto no Tratado, é "preciso" concluir que "o discurso faz ser, e é por isso que seu sentido só pode ser apreendido a posteriori, em vista do mundo que ele produziu." (p. 63).

Como conclusão, portanto, na ontologia o discurso tem a "função" de dizer o Ser, comemorar o Ser, "o de fora se impõe e impõe que se o diga" (p. 63), mas, para Górgias, o ser é um efeito do dizer, pois é o discurso quem faz ser, quem produz o de fora. O discurso, então, é demiúrgico, fabrica o mundo, faz com que ele advenha.

\section{Considerações finais}

Chegado o momento final, nossa conclusão existe apenas por uma questão de "método", e isso por dois motivos, a saber, temos como intenção apenas expor uma possível interpretação do texto de Górgias - interpretação essa inspirada essencialmente na interpretação de uma única autora (e as várias outras leituras, antigas e atuais, do Tratado muitas vezes divergem consideravelmente desta, mas essa é a que mais concordamos atualmente, apesar de algumas ressalvas não explicitadas devido à economia de nosso texto); e, pensamos que "concluir" algo sobre Górgias, ou sobre quaisquer de seus pouquíssimos fragmentos sobreviventes, de forma categórica é incoerente com o que o próprio Górgias combatia em sua perspectiva: a identificação ou adequação de um discurso a uma realidade prévia, "primeira", “originária", absolutamente verdadeira; o estabelecimento de verdades incontestáveis.

Do que foi exposto, cremos ter conseguido expressar que nosso autor não pretende estabelecer dogmaticamente o que seria $a$ realidade ou $a$ verdade, elas não seriam uma correspondência com um suposto ser das origens, pelo contrário, cremos que sua intenção é justamente a de "denunciar" que a ideia de uma verdade/realidade absoluta é algo bem explorado pelos filósofos de então através do bom uso dos discursos. E assim, uma das consequências disso também é que Górgias nos expõe a filosofia como um "fato de linguagem".

Em lugar então dessa ontologia ou filosofia que busca, seja sob a forma de elemento "natural" ou de "ideia", um fundamento da realidade - que é apenas uma dentre várias

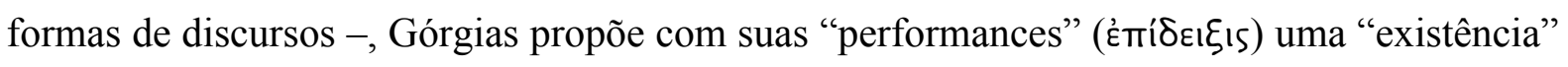


que "na medida em que é, é sempre apenas um efeito de dizer". ${ }^{14}$ Falta, e cabe, ainda perguntar sobre que realidade seria essa, que existência seria essa "produzida" pelo discurso.

Exatamente essa pólis grega, que é continuamente construída através da produção da homónoia (uma espécie de identidade de pensamento) e da homología (identidade de discurso), normalmente traduzidas como "consenso", "concórdia”, “acordo". Essa identidade de ideia entre si mesmo e entre os homens de uma cidade, longe de ser um "princípio de igualdade a si mesmo, de unidade e de unicidade intemporal colocado pelo eleatismo [...] e pela física jônica" 15 , é, ao contrário, algo a ser construído e conquistado ininterruptamente por meio dos discursos. Portanto, a "ordem" de uma cidade não estaria de acordo com uma Justiça "natural", mas sim, seria constantemente definida pelo homem através de seus discursos.

Pensamos, portanto, que - diferente do que dizia Platão e outros "acusadores" posteriores - Górgias não se refugia no não-ser do ser, no irracional, na falsidade, na aparência enfim, mas, justamente, torna evidente que as fronteiras como racional/irracional, verdade/falsidade, realidade/aparência são criações discursivas e o interesse unilateral de seus antecessores e contemporâneos no primeiro dos dois "polos" dessas dicotomias não é "desinteressado" e, talvez, exatamente por isso a filosofia posterior quis por tanto tempo reduzi-lo, junto com os demais "sofistas", ao silêncio ou remetê-lo exatamente àquilo que ele próprio combate.

\section{Referências bibliográficas}

\section{I - Textos e traduções de Górgias}

DIELS, Hermann. Die fragmente der vorsokratiker: grieschish und deutsch. 6. Berlin: Weidemann, 1952, 3v.

GÓRGIAS. O Tratado do Não-Ser, M.X.G./Sexto. Elogio de Helena. In: CASSIN, Barbara. $O$ efeito sofístico. Ana Lúcia de Oliveira e Maria Cristina Franco Ferraz. Rio de Janeiro: Editora 34, 2005.

GÓRGIAS. Testemunhos e Fragmentos. Trad. port. Manuel Barbosa e Inês de Ornellas e Castro. Lisboa: Edições Colibri, 1993.

GÓRGIAS, Tratado do Não-Ente. Elogio de Helena. Tradução, Introdução e comentários de COELHO, M. C. M. N.. Cadernos de Tradução, nº 4. São Paulo: USP, 1999.

\footnotetext{
${ }^{14}$ CASSIN, Barbara. Do chien-loup ou: a sofística, fato de história, efeito de estrutura. In: Ensaios sofísticos. Trad. bras. Ana Lúcia de Oliveira e Lúcia Cláudia Leão. São Paulo, Siciliano, 1990, p. 11.

${ }^{15}$ CASSIN, Barbara. A verdade de Antifon: uma democracia sádica. In: Ensaios sofísticos. Trad. bras. Ana Lúcia de Oliveira e Lúcia Cláudia Leão. São Paulo, Siciliano, 1990, pp. 143.
} 
GÓRGIAS. Tratado sobre o não-ser ou sobre a natura. Defesa de Palamedes. In: MARTINEZ, Josiane. A Defesa de Palamedes e sua articulação com o Tratado sobre o nãoser de Górgias. Tese de doutorado. Programa de Pós-Graduação em Linguística, Universidade Estadual de Campinas, Campinas, 2008.

SOFISTAS. Testemunhos e Fragmentos. Trad. port. Ana Maria Alexandre Alves de Sousa e Maria José Vaz Pinto. Lisboa: Imprensa Nacional-Casa da Moeda, 2005.

\section{II - Textos antigos}

PARMÊNIDES. Sobre a Natureza. Trad. bras. José Cavalcante de Souza. In: Os Présocráticos: Fragmentos, doxografia e comentários. São Paulo: Abril Cultural, 1978.

PARMÊNIDES. Da natureza. Tradução, introdução e comentário de SANTOS, José Trindade. São Paulo: Loyola, 2002.

PLATÃO. Sofista. Trad. port. Henrique Murachco, Juvino Maia Jr. e José Trindade Santos. Lisboa: Fundação Calouste Gulbenkian, 2011.

\section{III - Textos Modernos}

CASSIN, Barbara. O efeito sofístico. Ana Lúcia de Oliveira e Maria Cristina Franco Ferraz. Rio de Janeiro: Editora 34, 2005. . Ensaios sofísticos. Trad. bras. Ana Lúcia de Oliveira e Lúcia Cláudia Leão. São Paulo, Siciliano, 1990.

. "Barbarizar" e "cidadanizar" ou Não se escapa de Antifonte. In:

Gregos, Bárbaros, Estrangeiros - A cidade e seus outros. Rio de Janeiro, Ed. 34, 1993.

. Consenso e criação de valores - O que é um elogio? In: Gregos,

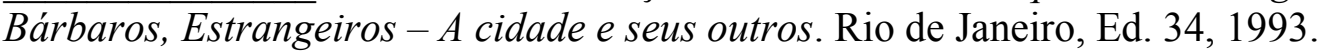

COELHO, M. C. M. N.. Retórica, filosofia e lógica: verdade como construção discursiva. In: Assunção, T.R., Flores, O., Martinho, M.. (Org.). Ensaios de Retórica. Belo Horizonte: Tessitura, 2010, v., p.p. 27-55.

- As afecções do corpo e da alma: a analogia gorgiana entre pharmakon e logos. In: PEIXOTO, M.C.D.. (Org.). A saúde dos antigos: reflexões gregas e romanas. São Paulo: Loyola, 2009, v. 1, p. 67-86.

KAHN, C. H. The greek verb 'to be' and the concept of being, Foundations of Language, vol. 2, pp.245-265, 1966.

KERFERD, G. B. O movimento sofista. Trad. bras. Margarida Oliva. São Paulo: Edições Loyola, 2003.

MARTINEZ, Josiane. A Defesa de Palamedes e sua articulação com o Tratado sobre o nãoser de Górgias. Tese de doutorado. Programa de Pós-Graduação em Linguística, Universidade Estadual de Campinas, Campinas, 2008.

MARQUES, Marcelo Pimenta. Platão, pensador da diferença. Uma leitura do Sofista. Belo Horizonte: Editora UFMG, 2006.

UNTERSTEINER, Mario. A obra dos sofistas: uma interpretação filosófica. Trad. port. Renato Ambrósio. São Paulo: Paulus, 2012. 